\title{
Implementasi Prototype Aplikasi Pengelolaan Inventaris Barang
}

\author{
Martono \\ Program Studi Teknik Informatika, STIKOM Dinamika Bangsa, Jambi \\ Jl. Jendral Sudirman Thehok - Jambi Telp.(0741)35095,Fax.(0741) 35093 \\ E-mail:martono@stikom-db.ac.id
}

\begin{abstract}
Applications are generally built with the aim to facilitating human work. Almost all aspects use applications to facilitate human work. One example is the use of applications to assist in the management of inventory. As for this research will be carried out the implementation of the prototype that the writer has built in previous research. The results of the implementation of the inventory management prototype application that was built in this study will replace the process of managing inventory data of items that were previously done manually to be computerized. The application built in this study was built using the waterfall system design method. Where in the previous research the author arrived at the design stage of the prototype and in this research the implementation phase will be carried out. The inventory management application that was built in this study has a management function of inventory data, starting from item type grouping, buying, selling and stocking of available items to managing reports. With the implementation of this application, it can have an effect on efficiency in terms of time and cost in terms of managing inventory data, increasing data accuracy and minimizing the risk of loss of inventory data if stored in paper media.
\end{abstract}

Keywords: Implementation, Prototype, Appication, Inventory.

\begin{abstract}
Abstrak
Aplikasi umumnya dibangun dengan tujuan untuk mempermudah pekerjaan manusia. Hampir seluruh aspek menggunakan aplikasi untuk mempermudah pekerjaan manusia. Salah satu contohnya adalah pemanfaatan aplikasi untuk membantu dalam pengelolaan stok barang. Adapun pada penelitian ini akan dilakukan pengimplementasian terhadap prototype yang telah penulis bangun pada penelitian sebelumnya. Hasil implementasi prototype aplikasi pengelolaan inventaris barang yang dibangun pada penelitian ini akan menggantikan proses pengelolaan data inventaris barang yang sebelumnya dilakukan secara manual menjadi terkomputerisasi. Aplikasi yang dibangun pada penelitian ini dibangun menggunakan metode perancangan sistem waterfall. Dimana pada penelitian sebelumnya penulis telah sampai pada tahap perancangan prototype dan pada penelitian ini akan dilakukan tahap implementasi. Aplikasi pengelolaan inventaris barang yang yang dibangun pada penelitian ini memiliki fungsi pengelolaan terhadap data barang, dimulai dari pengelompokan jenis barang, pembelian, penjualan dan stok barang yang tersedia hingga pengelolaan laporan. Dengan diterapkannya aplikasi ini dapat memberikan dampak efisiensi dari segi waktu dan biaya dalam hal pengelolaan data inventaris barang, meningkatkan keakuratan data serta meminimalisir resiko atas kehilangan data barang jika disimpan dalam bentuk media kertas.
\end{abstract}

Kata Kunci: Implementasi, Prototype, Aplikasi, Inventaris.

(C) 2019 Jurnal Ilmiah MEDIA SISFO

\section{Pendahuluan}

Penggunaan teknologi informasi yang diterapkan melalui sistem informasi memberikan kemudahan kepada pengguna dalam melaksanankan pekerjaannya. Kemudahan yang diperoleh dalam penggunaan sistem informasi yaitu memudahkan dalam mengelola data serta memudahkan pada saat melakukan 
evaluasi data berdasarkan kebutuhan. Secara umum persepsi pengelolaan terhadap peran sistem informasi manajemen berbasis teknologi informasi dalam pengelolaan data yang sangat penting, karena tidak jarang dengan banyaknya jumlah perusahan disuatu suatu lokasi sulit dikontrol sehingga ada kemungkinan terjadi pelaporan yang tidak sama.[1]

Salah satu permasalahan yang dapat diselesaikan dengan memanfaatkan teknologi informasi adalah dalam hal pengelolaan data. Pengelolaan data barang atau pengelolaan data inventaris barang pada suatu perusahaan merupakan salah satu permasalahan yang dapat diselesaikan dengan menggunakan teknologi. Umumnya perusahaan akan menggunakan metode lama dengan memanfaatkan media kertas sebagai opsi utama dalam hal pengelolaan stok barang. Pemanfaatan media kertas ini di nilai kurang efektif dan efisien. Dari segi waktu, karyawan akan membutuhkan lebih banyak waktu dan tenaga untuk mencari suatu data barang. Dari aspek biaya, penyimpanan dengan media kertas akan memakan lebih banyak ruang. Tidak hanya itu, tingginya resiko kerusakan, kehilangan serta kurangnya akurasi data barang jika disimpan dalam media kertas menjadikan teknologi sebagai solusi atas permasalahan dari pemanfaatan media kertas sebagai media penyimpanan.

Berdasarkan permasalahan diatas, maka dapat disimpulkan bahwa metode yang dapat dipergunakan untuk mempermudah proses pemeriksaan stok barang sehingga selalu sesuai dengan keadaan pada tempat penyimpanan adalah dengan memanfaatkan aplikasi pengelolaan inventaris barang.

Pada penelitian yang telah penulis lakukan sebelumnya, aplikasi pengelolaan inventaris barang yang dirancang masih terbatas hingga tahap perancangan prototype. Pada penelitian ini akan dilakukan tahap berikutnya yaitu tahap implementasi dan pengujian terhadap sistem pengelolaan inventaris barang yang telah penulis bangun.

Tujuan dari penelitian ini adalah untuk menghasilkan sebuah aplikasi pengelolaan inventaris barang yang telah dapat dipergunakan oleh administrator dan operator yang memiliki tugas yang berhubungan dalam pengelolaan inventaris barang sesuai dengan prototype aplikasi pengelolaan inventaris barang yang telah penulis buat pada penelitian sebelumnya. Sehingga baik administrator maupun operator dapat saling terhubung melalui satu aplikasi yang sama sehingga setiap proses transaksi yang terjadi jumlah inventaris yang tersedia akan selalu sesuai dengan jumlah stok yang ada ada tempat penyimpanan barang sehingga pada saat pengecekan jumlah inventaris barang yang perlu ditambahkan ataupun inventaris yang perlu diperbaiki menjadi lebih mudah dan efisien.

\section{Tinjauan Pustaka}

\subsection{Landasan Teori}

Tahapan kegiatan dari pembangunan perangkat lunak secara umum adalah : [2]

1. Requirement gathering (analisis kebutuhan) merupakan tahapan kegiatan untuk memperoleh spesifikasi terhadap perangkat lunak yang dibangun melalui survey, tanya jawab dan wawancara dengan pengguna.

2. System analysis (analisis sistem) merupakan kegiatan untuk menganalisa spesifikasi perangkat lunak yang telah didapat.

3. Design (perancangan) merupakan tahap pembangunan model perangkat lunak. Model yang dibangun antarra lain antarmuka, perancangan basis data, pseudo code, dan lain-lain.

4. Implementation (implementasi) merupakan tahapan implementasi dalam pembangunan perangkat lunak, biasanya disebut dengan fase coding.

5. Testing (pengujian) untuk menguji perangkat lunak. Pengujian dapat dilakukan dengan cara mengecek input dan output dan mengecek kode.

6. Deploy and Maintenance (persiapan dan pemeliharaan) merupakan tahapan untuk instalasi perangkat lunak yang dibuat kepada organisasi atau perusahaan pengguna serta memeliharanya.

Implementasi merupakan tahap realisasi tujuan-tujuan program. Dalam hal ini yang perlu diperhatikan adalah persiapan implementasi, yaitu memikirkan dan menghitung secara matang berbagai kemungkinan keberhasilan dan kegagalan, termasuk hambatan dan peluang-peluang yang ada dan kemampuan organisasi yang diserahkan tugas melaksanakan program [3]. Tahap implementasi juga dapat diartikan sebagai realisasi terhadap program pelatihan yang telah didesain dan dikembangkan sebelumnya [4]. 
Program dalam konteks implementasi aplikasi pengelolaan inventaris barang pada penelitian ini telah melalui tahapan rancang bangun prototype (Design) dan berada dalam tahap implementasi, dimana prototype aplikasi yang telah dibuat akan dibangun sehingga dapat dipergunakan sebagaimana mestinya.

Aplikasi adalah suatu perangkat lunak yang terdiri dari fungsi-fungsi atau perintah-perintah yang dapat dipergunakan oleh pengguna dalam melakukan suatu tugas [5]. Aplikasi juga dapat berarti sebagai sebuah program atau perangkat lunak yang dibangun untuk tujuan tertentu dengan menjalankan aktivitas atau perintah sesuai dengan fungsi yang dimiliki sehingga dapat menjalankan fungsinya sesuai dengan keinginan pengguna aplikasi [6].

Aplikasi bisa berisi :

1. Suatu antarmuka: Menus, window dan kontrol window dimana user berinteraksi langsung dengan aplikasi.

2. Proses logika aplikasi: kejadian (Event) dan funsi skrip yang dibuat sebagai logika aplikasi, validasi dan proses logika sebagai bagian dari antarmuka atau dibuat dalam modul-modul yang terpisah sebagai objek yang dibuat sendiri yang dinamakan custom class user objects.

Tidak bisa dipungkiri memang dibutuhkan modal usaha untuk memulai suatu usaha. Hanya saja kebutuhan modal usaha ditentukan jumlahnya oleh besar kecilnya skala usaha. Jenis modal usaha terbagi menjadi dua jenis yaitu modal investasi dan modal kerja. Modal investasi adalah modal awal yang diperlukan untuk investasi awal usaha. Modal investasi dikeluarkan untuk membeli kebutuhan usaha yang teta atau harta tetap. Sementara modal kerja merupakan modal yang dibutuhkan untuk membiayai operasional usaha. Modal yang penting untuk dikelola ketika usaha telah berjalan yaitu modal investasi, seperti peralatan administrasi, alat promosi dan aneka peralatan kebutuhan pokok untuk usaha. [7]

Setiap pengusaha berkepentingan untuk mengetahui secara detail semua barang yang menjadi harta kekayaannya. Setiap adanya penambahan dan pengurangan barang, berarti penambahan dan pengurangan harta kekayaan. Oleh sebab itu, penting bagi pengusaha untuk menyelenggarakan inventarisasi barang secara terperinci, lengkap dan teratur. Inventarisasi merupakan kegiatan untuk mencatat dan menyusun daftar barang secara teratur. Dengan kegiatan inventarisasi terhadap barangbarang yang ada, maka akan dapat membantu dalam membuat perencanaan kebutuhan. [8]

Pencatatan atau inventaris barang berguna untuk mengetahui jumlah peralatan dan perlengkapan usaha. Peralatan dan perlengkapan yang sering fipakai kemungkinan akan rusak dan hilang sehingga pemilik harus melakukan pencatatan dan pemeriksaan pada perlengkapan agar dapat terus memantau jumlah dan kondisi barang usahanya. [9]

\section{Metodologi}

\subsection{Metode Pengumpulan Data}

Metode pengumpulan data yang penulis gunakan dalam penelitian ini adalah studi pustaka. Dalam studi pustaka penulis mengumpulkan data dan informasi yang relevan dengan topik atau masalah yang akan diteliti. Data dan informasi tersebut penulis peroleh dari buku-buku ilmiah, karangan-karangan ilmiah, laporan penelitian, dan sumber-sumber tertulis lainnya baik cetak maupun elektronik, termasuk penelitian-penelitian terdahulu yang bersumber dari perpustakaan dan internet.

\subsection{Metode Pengembangan Sistem}

Adapun metode yang digunakan dalam pengembangan sistem pada penelitian ini adalah metode waterfall. Model waterfall adalah sebuah permodelan yang terdiri dari 5 tahapan yaitu tahap analisis kebutuhan, desain sistem, implementasi sistem, pengujian sistem dan maintenance / perawatan. Pada penelitian ini dilakukan tahap implementasi dan pengujian sistem dari hasil prototype yang telah penulis bengun pada penelitian yang sebelumnya dengan menggunakan bahasa pemrograman java dan database MySQL dan kemudian dilakukan pengujian terhadap aplikasi yang telah dibangun untuk mengetahui apakah aplikasi yang dibangun telah berjalan sesuai dengan fungsinya dengan menggunakan metode blackbox. 


\section{Hasil dan Pembahasan}

\subsection{Analisis Sistem}

Analisis sistem dilakukan dengan pendekatan analisis berorientasi objek menggunakan Unified Modeling Language (UML). Penggunaan Unified Modeling Language (UML) ini diharapkan dapat menampilkan kebutuhan sistem berupa interaksi sistem dengan lingkungannya dan fungsionalitasnya. Diagram Unified Modeling Language (UML) yang digunakan dalam analisis sistem ini adalah use case diagram.

Pada tahap analisis sistem ini dilakukan analisis terhadap kekurangan dari sistem sejenis yang telah terlebih dahulu dibangun secara lebih detail mulai dari proses pengolahan data, prosedur, fungsi dan tahapan-tahapan dalam penggunaan aplikasi yang akan dirancang sehingga dapat dimodifikasi menjadi sebuah rancangan aplikasi yang lebih baik. Berikut merupakan use case dari prototype sistem pengelolaan inventaris barang yang telah dibuat oleh penulis pada penelitian sebelumnya dan yang akan diimplementasikan pada penelitian ini:

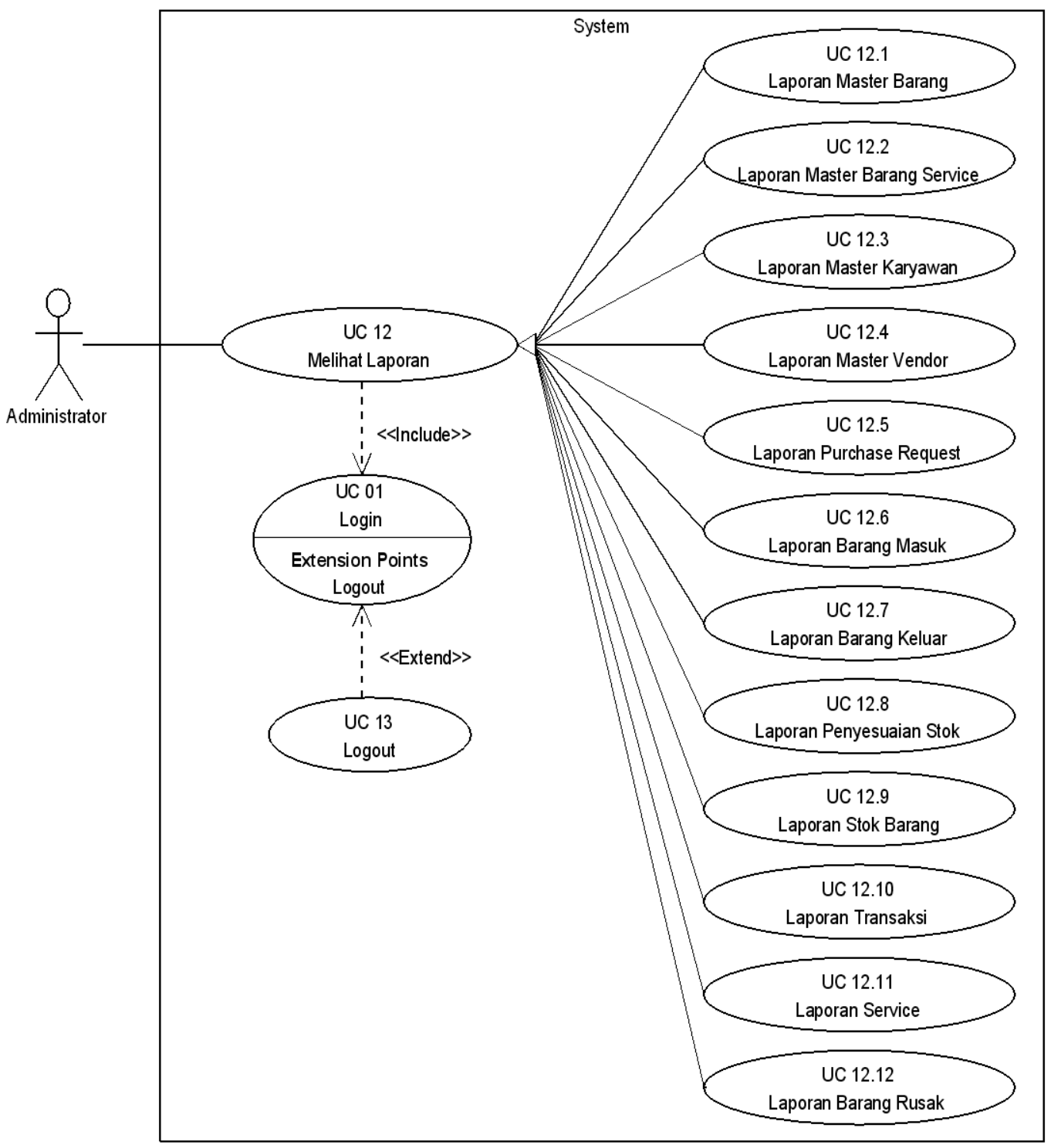

Gambar 1. Use Case Aplikasi Pengelolaan Inventaris Barang dengan User Administrator 1 [10] 


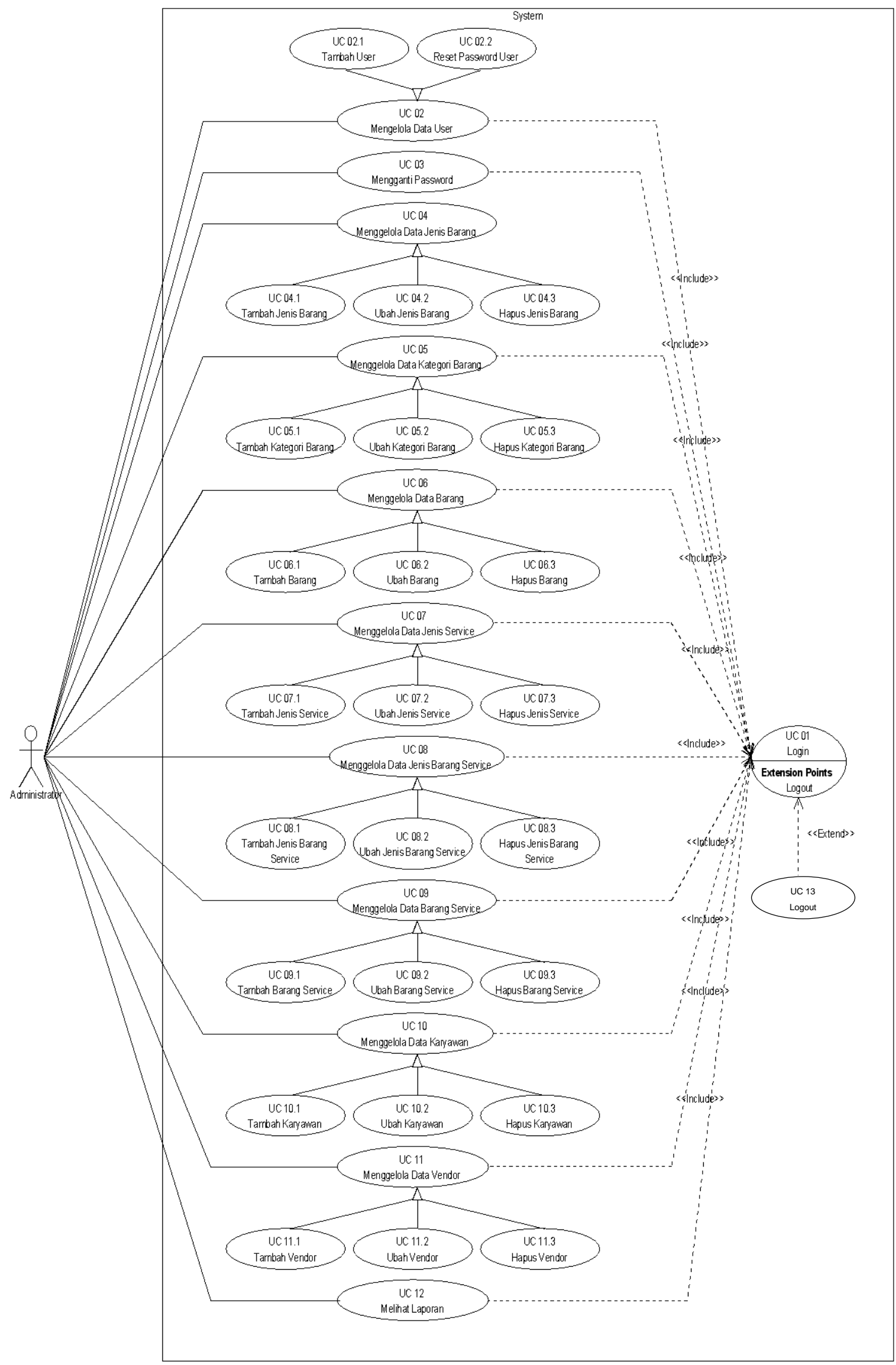

Gambar 2. Use Case Aplikasi Pengelolaan Inventaris Barang dengan User Administrator 2 [10] 


\subsection{Implementasi Sistem}

Pada tahap ini fungsi-fungsi aplikasi disusun sedemikian rupa sehingga aplikasi dapat berjalan sebagaimana yang diharapkan sehingga dapat mencapai hasil yang dinginkan. Berikut merupakan beberapa gambar dari hasil implementasi aplikasi pengelolaan inventaris barang yang dirancang pada penelitian ini, yaitu:

\section{Halaman Login}

Halaman login merupakan halaman pertama yang tampil ketika pengguna aplikasi (Administrator dan Operator) menjalankan aplikasi pengelolaan inventaris barang. Halaman ini berfungsi untuk menjaga agar data dalam aplikasi tidak dapat diakses oleh pihak yang tidak memiliki otoritas untuk mengakses dan mengubah data.

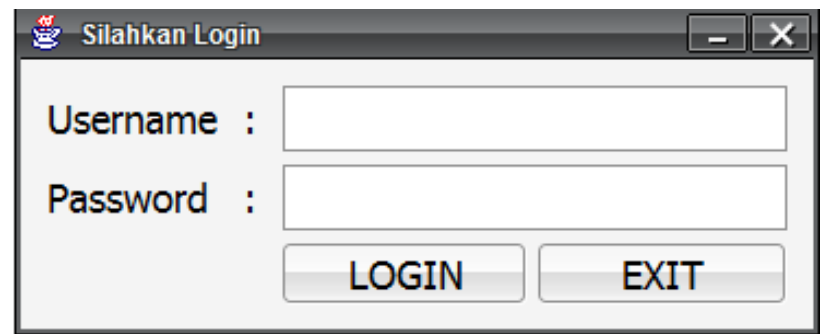

Gambar 3. Halaman Login

2. Halaman Master Vendor

Halaman master vendor merupakan halaman yang dapat diakses oleh pengguna aplikasi dengan level Administrator maupun Operator. Halaman ini berfungsi untuk menampilkan data-data vendor yang terdiri dari nama vendor, nomor telepon vendor, alamat dan keterangan. Untuk mengakses halaman ini, pengguna aplikasi harus mengklik tombol master vendor terlebih dahulu. Melalui halaman master vendor, pengguna dapat mengelola data vendor dengan mengklik tombol tambah untuk menambah data vendor, tombol ubah untuk mengubah data vendor, tombol hapus untuk menghapus data vendor, tombol refresh untuk me-refresh halaman master vendor dan tombol kembali untuk kembali ke halaman utama aplikasi pengelolaan inventaris barang.

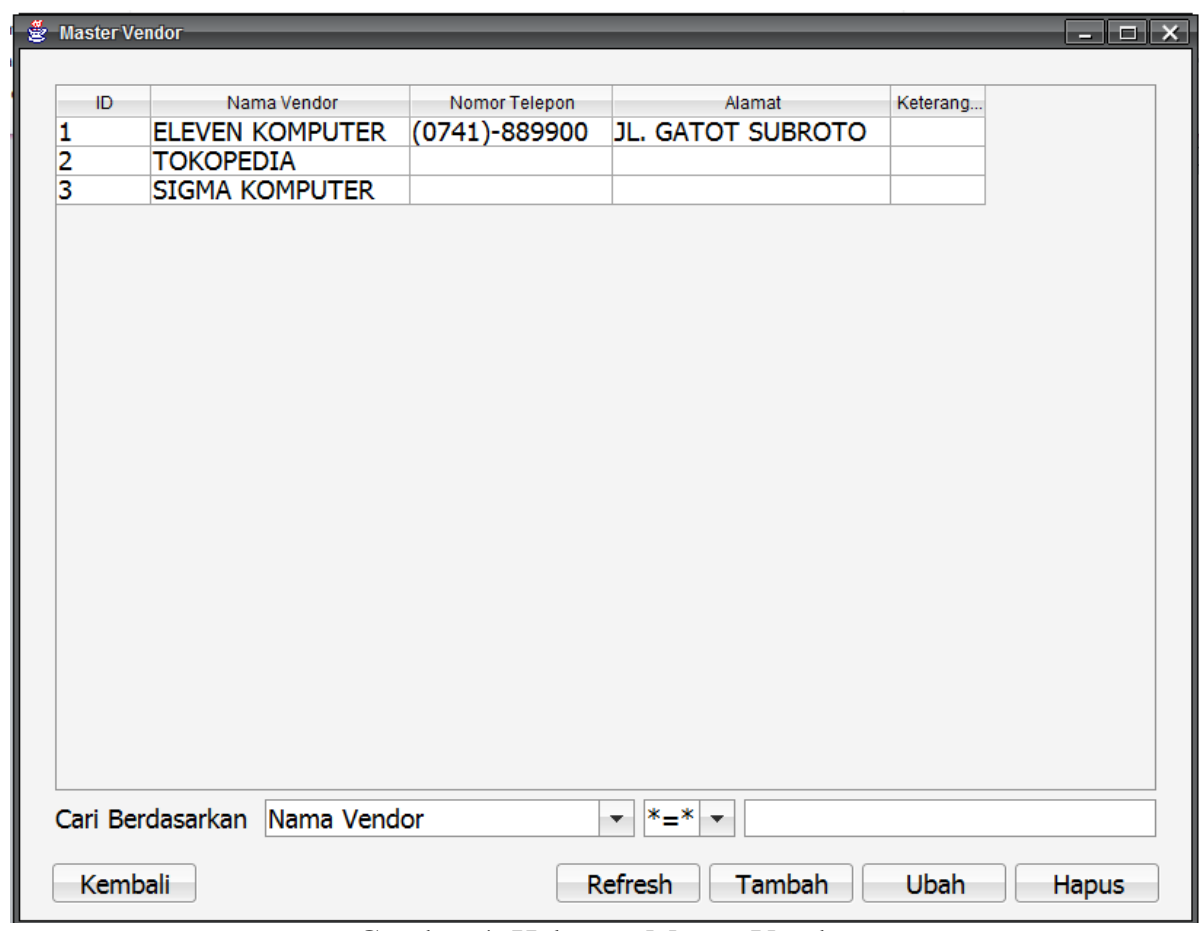

Gambar 4. Halaman Master Vendor 
3. Halaman Tambah Vendor

Halaman tambah vendor merupakan halaman yang memungkinkan pengguna aplikasi (Administrator dan Operator) untuk melakukan penambahan data vendor ke dalam aplikasi. Halaman tambah data vendor dapat diakses melalui tombol tambah yang ada pada halaman master vendor.

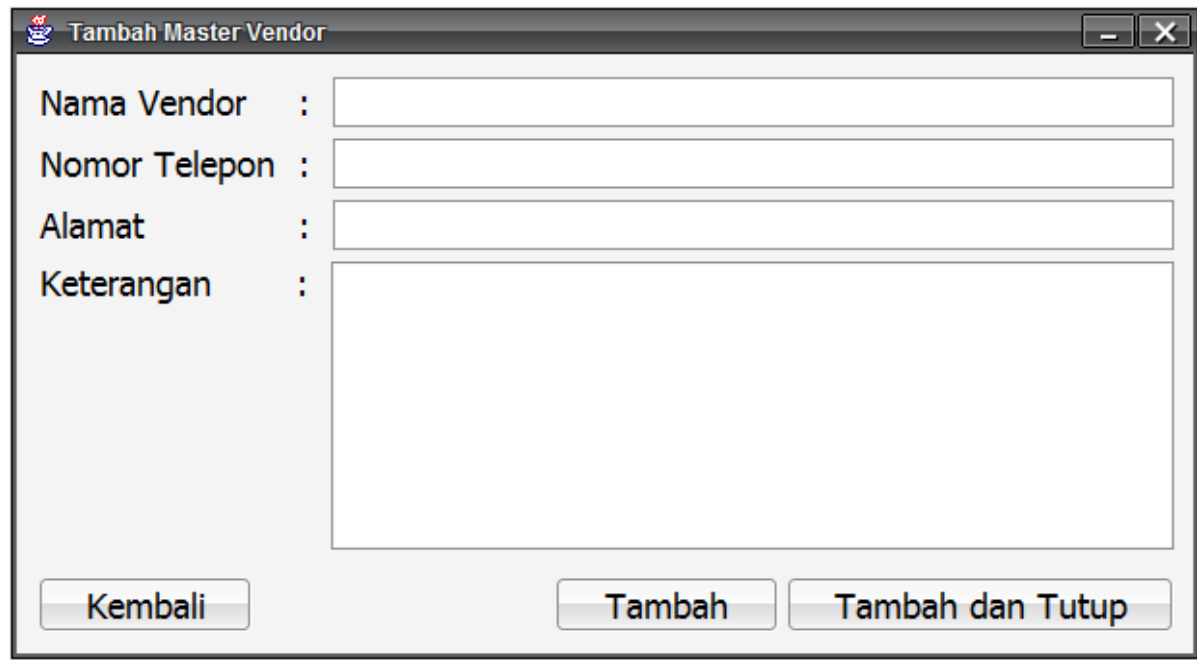

Gambar 5. Halaman Tambah Vendor

4. Halaman Ubah Vendor

Halaman ubah vendor merupakan halaman yang memungkinkan pengguna aplikasi (Administrator dan Operator) untuk melakukan perubahan terhadap data vendor yang telah ada dalam aplikasi. Halaman ubah data vendor dapat diakses dengan cara memilih data vendor yang ingin di ubah dan kemudian mengklik tombol ubah yang ada pada halaman master vendor.

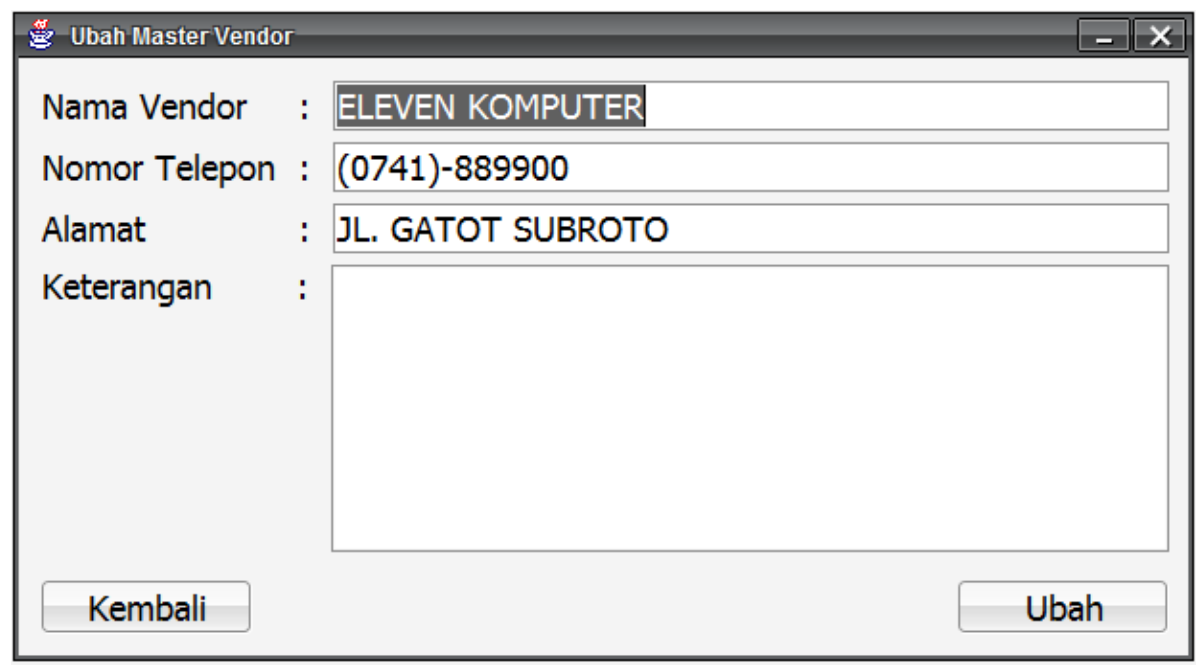

Gambar 6. Halaman Ubah Vendor

5. Halaman Hapus Vendor

Halaman hapus vendor merupakan halaman yang memungkinkan pengguna aplikasi (Administrator dan Operator) untuk melakukan penghapusan pada data vendor yang telah ada dalam aplikasi. Halaman hapus data vendor dapat diakses dengan cara memilih data vendor yang ingin dihapus dan kemudian mengklik tombol hapus yang ada pada halaman master vendor. 


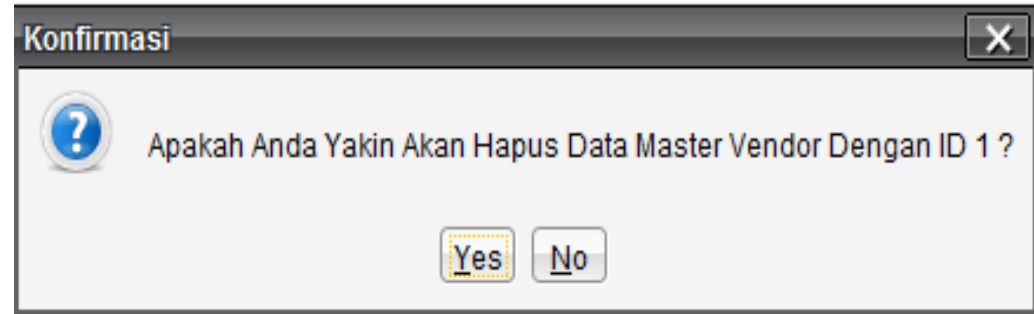

Gambar 7. Halaman Hapus Vendor

6. Laporan Master Barang

Laporan master barang merupakan laporan yang berisikan data-data barang yang ada dalam aplikasi yang kemudian disusun dalam bentuk tabel untuk kemudian dicetak sebagai laporan. Laporan master barang dapat diakses oleh pengguna (Administrator dan Operator) melalui menu laporan master barang yang ada pada halaman utama aplikasi pengelolaan inventaris barang.

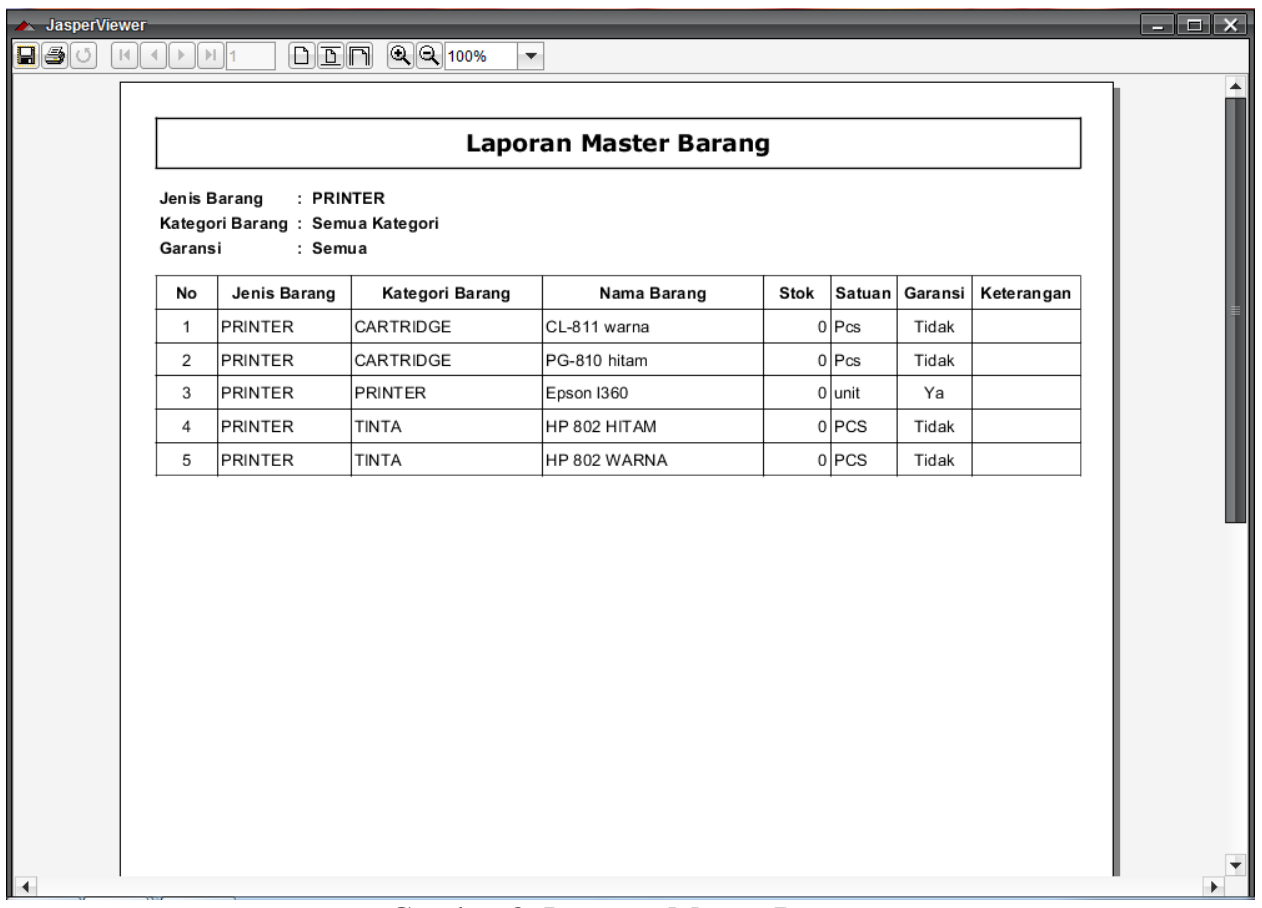

Gambar 8. Laporan Master Barang

7. Laporan Purchase Request

Laporan purchase request merupakan laporan yang berisikan daftar barang yang ingin dibeli (menunggu persetujuan pembelian) yang disusun dalam bentuk tabel untuk kemudian dicetak sebagai laporan. Laporan puchase request dapat diakses oleh pengguna (Administrator dan Operator) melalui menu laporan purchase request yang ada pada halaman utama aplikasi pengelolaan inventaris barang. 


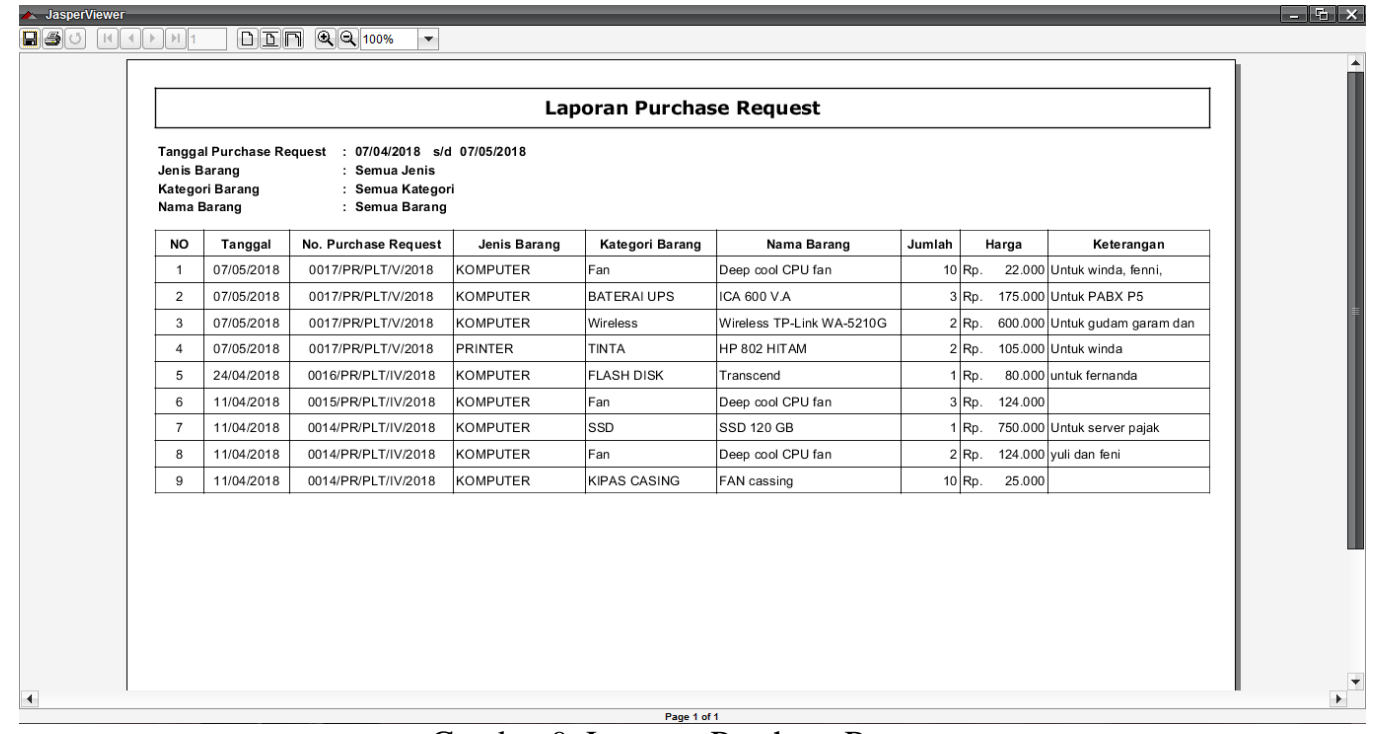

Gambar 9. Laporan Purchase Request

\subsection{Pengujian Sistem}

Tujuan pengujian sistem adalah untuk mengurangi atau bahkan menghilangkan kesalahan yang mungkin ada pada sebuah sistem dan untuk mengetahui apakah sistem yang dihasilkan telah mencapai tujuan yang diharapkan sehingga dapat dijadikan solusi dari permasalahan yang ada. Pengujian sistem dilakukan dengan metode blackbox, yaitu metode pengujian yang dilakukan dengan mengamati hasil eksekusi melalui data uji dan memeriksa fungsionalitas dari program.

Pada metode blackbox pengujian dilakukan dengan cara menjalankan dan mengeksekusi tiap modul program kemudian dilakukan pengamatan pada hasil atau output dari proses tersebut, apakah sudah sesuai dengan proses yang dikehendaki sehingga akan diketahui jika ada kesalahan atau bugs. Berdasarkan hasil pengujian yang telah penulis lakukan pada sistem yang dihasilkan, maka dapat diambil kesimpulan bahwa sistem yang dibangun sudah benar sesuai dengan yang dibutuhkan dan sudah berjalan sesuai dengan fungsionalitas yang diharapkan dari sistem tersebut.

\section{Kesimpulan}

\subsection{Simpulan}

Berdasarkan hasil penelitian yang telah penulis lakukan mengenai implementasi aplikasi pengelolaan inventaris barang, maka dapat diambil kesimpulan sebagai berikut:

1. Hasil dari penelitian ini adalah sebuah aplikasi yang dapat melakukan pengelolaan terhadap data inventaris barang yang dapat memberikan efisiensi dalam hal biaya dan waktu pemrosesan data, aplikasi ini juga dapat meningkatkan keakuratan data karena hanya dapat diakses oleh orang yang memiliki otoritas terhadap data inventaris barang dan mengurangi resiko kehilangan data inventaris barang karena telah disimpan dalam media digital.

2. Berdasarkan hasil pengujian yang telah penulis lakukan dengan menggunakan metode blackbox, diperoleh bahwa aplikasi pengelolaan inventaris barang yang dibangun pada penelitian ini telah berfungsi dan berjalan sesuai dengan yang diharapkan.

\subsection{Saran}

Berdasarkan hasil penelitian mengenai implementasi aplikasi pengelolaan inventaris barang, maka dapat diberikan saran agar penelitian ini dapat diteruskan hingga tahap maintenance/perawatan sehingga aplikasi yang pengelolaan inventaris barang yang dibangun pada penelitian ini dapat dikembangkan lebih lanjut sesuai dengan perkembangan teknologi dan kebutuhan penggunanya. 


\section{Daftar Rujukan}

[1] Rukoyah, A. S., Abidillah, G., \& Hadiana, A. I. (2017). Sistem Informasi Inventaris Barang pada RSUD Soreang. Prosiding SNATIF, 869-874.

[2] Feri Sulianta., Fajri Rakhmat Umbara. 2015. Teknik Hebat Merancang Aplikasi Instan dan Berkualitas. Jakarta : Elex Media Komputindo.

[3] Rahmat Alyakin Dachi. 2017. Proses dan Analisis Kebijakan Kesehatan. Yogyakarta : Deepublish.

[4] Benny A. Pribadi., 2016. Desain dan Pengembangan Program Pelatihan Berbasis Kompetensi : Implementasi Model Addie. Jakarta : Kencana.

[5] Kathryn McElroy. 2017. Prototyping for Designers: Developing the Best Digital and Physical Products. USA : Oreilly Media.

[6] Nadia Firly. 2018. Create Your Own Android Application. Jakarta : Elex Media Komputindo.

[7] Sean Putman. 2014. Using Prototyping in Instructural Design. USA : Learning Technologies.

[8] Stuart G Mccrady. 2013. Designing Scada Application Software : A Practical Approach. Canada : Elsevier.

[9] Wulan Ayogya. 2010. Cara Jitu Hitung Modal Usaha. Jakarta : Elex Media Komputindo.

[10] Martono, M. (2018). Perancangan Prototype Aplikasi Pengelolaan Inventaris Barang. Jurnal Ilmiah Media Sisfo, 12(2), 1099-1110. 